\title{
Dietary n-3 polyunsaturated fatty acids ameliorate Crohn's disease in rats by modulating the expression of PPAR- $\gamma /$ NFAT
}

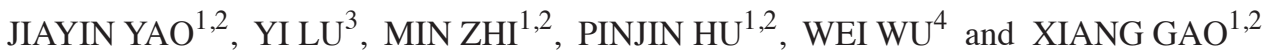 \\ ${ }^{1}$ Department of Gastroenterology; ${ }^{2}$ Guangdong Provincial Key Laboratory of Colorectal and Pelvic Floor Diseases, \\ The Sixth Affiliated Hospital of Sun Yat-Sen University, Guangzhou, Guangdong 510655; ${ }^{3}$ Department of Anesthesiology, \\ Guangzhou Hospital of Traditional Chinese Medicine, Guangzhou, Guangdong 510130; 'Department of Cardiology, \\ Sun Yat-Sen Memorial Hospital, Sun Yat-Sen University, Guangzhou, Guangdong 510235, P.R. China
}

Received January 1, 2017; Accepted August 7, 2017

DOI: $10.3892 / \mathrm{mmr} .2017 .7673$

\begin{abstract}
Dietary n-3 polyunsaturated fatty acid (PUFA) exerts anti-inflammatory and immunoregulatory effects via downregulation of the innate and adaptive immune responses. However, the effect of dietary n-3 PUFA on experimental Crohn's Disease (CD) in rats and the underlying mechanisms are unclear. The present study aimed to investigate the effects of n-3 PUFA on CD induced by 2,4,6-trinitrobenzene sulfonic acid (TNBS) in rats, and to determine the underlying mechanisms, including the peroxisome proliferator-activated receptor (PPAR) $-\gamma$ and nuclear factor of activated T-cells (NFAT) pathway. Sprague-Dawley rats $(\mathrm{n}=90)$ were randomly assigned to the following groups: Control (intragastric distilled water); PUFA control (intragastric n-3 PUFA, $20 \mathrm{mg} / \mathrm{kg} /$ day); trans-fatty acid (TFA) control (intragastric TFA, $13 \mathrm{mg} / \mathrm{kg} /$ day); model (intragastric distilled water + TNBS); PUFA model (intragastric $\mathrm{n}-3$ PUFA, $20 \mathrm{mg} / \mathrm{kg} /$ day + TNBS); and TFA model (intragastric TFA, $13 \mathrm{mg} / \mathrm{kg} / \mathrm{day}+\mathrm{TNBS}$ ). The disease activity index (DAI), colon macroscopic damage index (CMDI) and tissue damage index (TDI) were evaluated. The expression of PPAR- $\gamma$, NFAT, interleukin (IL)- 4 and IL-2 mRNA in colonic tissues was determined by reverse transcription-quantitative polymerase chain reaction (RT-qPCR), and the serum levels of IL-6, IL-12, tumor necrosis factor- $\alpha$ and interferon- $\gamma$ were measured by ELISA. The results demonstrated that dietary n-3 PUFA markedly attenuated colonic inflammation compared with the model group, as indicated by reduced DAI, CMDI and TDI scores, amelioration in pathological evaluation and improvements in localized mucosal inflammation,
\end{abstract}

Correspondence to: Professor Xiang Gao, Department of Gastroenterology, The Sixth Affiliated Hospital of Sun Yat-Sen University, 26 Yuancun 2nd Cross Road, Guangzhou, Guangdong 510655, P.R. China

E-mail: doctorgaoxiang@yeah.net; helengao818@163.com

Key words: Crohn's disease, n-3 polyunsaturated fatty acids, peroxisome proliferator-activated receptor- $\gamma$, nuclear factor of activated T-cells, dietary therapy as indicated by the levels of cytokines associated with local mucosal immunity. Treatment with n-3 PUFA increased the gene expression of PPAR- $\gamma$ in TNBS-treated rats, and reduced the expression of NFAT, which ultimately reduced the release of IL-4 and IL-2 detected by RT-qPCR. A TFA-enriched diet was observed to increase DAI and TDI scores, aggravate pathological inflammation with epithelioid granulomas and enhance the release of proinflammatory cytokines, compared with the model group. In conclusion, the present study demonstrated that dietary n-3 PUFA may attenuate experimental CD induced by TNBS in rats by regulating the expression and activity of the PPAR- $\gamma /$ NFAT signaling pathway. These results provide a promising potential therapeutic method for the treatment of CD.

\section{Introduction}

Inflammatory bowel disease (IBD) consists of two types: Crohn's disease (CD) and ulcerative colitis (UC). Crohn's disease is a chronic immune-mediated inflammatory disorder of the gastrointestinal tract. It is widely accepted that the key mechanism underlying the development of $\mathrm{CD}$ is a dysregulated immune response to commensal flora in a genetically susceptible host $(1,2)$. However, the precise etiology remains to be determined, which leads to limitations of corresponding therapeutic methods.

Diet has been hypothesized to serve an important role in the pathogenesis and clinical course of $\mathrm{CD}$, as the incidence of $\mathrm{CD}$ has risen markedly in countries where a western diet culture prevails $(3,4)$. In particular, dietary fat may influence intestinal inflammation and regulate mucosal immunity, which is considered to be a core etiological factor and may be a promising therapeutic target for $\mathrm{CD}$.

The fatty acids that are consumed as part of our daily diets are broadly classified as cis- and trans-fatty acids (TFAs). N-3 polyunsaturated fatty acids (PUFAs) belong to the group of cis PUFAs, and include docosahexaenoic acid and eicosapentaenoic acid. Numerous previous studies have demonstrated that TFA consumption was a risk factor, while n-3 PUFA consumption was a protective factor, for various diseases associated with systemic or localized inflammation, including diabetes and coronary heart disease $(5,6)$. According to a retrospective study 
by Nanthakrishnan et al (5), which followed 170,805 women with IBD for 26 years, a high intake of dietary long-chain n-3 PUFA may be associated with a reduced risk of UC. By contrast, a high intake of TFA was reported be associated with an increased risk of UC (7). Dietary n-3 PUFA competitively inhibits the formation of proinflammatory prostaglandins and leukotrienes via the arachidonic acid pathway (8), and inhibits angiogenesis and adaptive immune responses $(9,10)$. However, the effect of dietary n-3 PUFA on CD and the underlying mechanisms remain unclear.

Peroxisome proliferator-activated receptor (PPAR)- $\gamma$ is a member of the nuclear receptor superfamily of ligand-dependent transcription factors, and is primarily expressed in adipose tissue and the colonic epithelium (11). Recently, its role in intestinal inflammation has emerged. Su et al (12) reported that the use of the PPAR- $\gamma$ synthetic agonist thiazolidinedione (TZD) markedly decreased colonic inflammation in mice with 2,4,6-trinitrobenzene sulfonic acid (TNBS)-induced colitis. These results were subsequently confirmed in different animal models with various models of colitis induced by chemical compounds (13), ischaemia (14) or genetically modified animals $(15,16)$. PPAR- $\gamma$ interferes with inflammatory pathways by antagonizing the activity of various transcription factors, such as nuclear factor of activated T-cells (NFAT). It is established that NFAT has an important function in the transcriptional induction of various proinflammatory genes, including interleukin (IL)-4 and IL-2, during T-cell activation $(17,18)$. Thus, PPAR- $\gamma$ may serve a key role in the regulation of adipocyte differentiation and inflammation. In addition, fatty acids and their metabolites are able to modulate PPAR- $\gamma$. The precise association between dietary fatty acids and the PPAR- $\gamma$ /NFAT pathway remains unknown.

In the current study, the primary objectives were to investigate the effect of long-term administration of an n-3 PUFA-enriched diet on CD rat models induced by TNBS, and to characterize the association between n-3 PUFA and PPAR- $\gamma /$ NFAT in intestinal inflammation. In addition, the current study aimed to determine whether n-3 PUFA may exhibit a potent anti-inflammatory effect in experimental CD rats, and whether the protective effect of this fatty acid involves the activation of PPAR- $\gamma$ and inhibition of NFAT.

\section{Materials and methods}

Ethics statement. The experiments in the present study were performed in conformity with the National Institutes of Health (NIH) (19) and Animal Research: Reporting in vivo Experiments (ARRIVE) guidelines (20), and were approved by the Animal Care and Use Committee of Sun Yat-Sen University (approval no. 20161652118). All surgical and experimental procedures were performed according to the guidelines for the care and use of animals approved by the Sun Yat-Sen University and were in accordance with the code of Ethics of the EU Directive 2010/63/EU for animal experiments. All efforts were made to minimize animal suffering and to reduce the number of animals used.

Animals. Specific pathogen free male Sprague-Dawley rats ( $n=90$; 6-week-old; weight, 180-220 g) were obtained from the Animal Experiment Center of the Sun Yat-Sen University.
Animals were maintained in controlled environment conditions with temperature $\left(23 \pm 1^{\circ} \mathrm{C}\right)$, humidity $(60 \pm 10 \%)$ and a 12-h light/dark cycle. They were housed in 15 cages each containing 6 rats and were allowed standard rat chow and water ad libitum.

Experimental design. Following 1-week acclimation, 90 Sprague-Dawley rats were randomly divided into the following 6 groups $(n=15)$ : Control, intragastric administration of distilled water; PUFA control, intragastric administration of $\mathrm{n}-3$ PUFA ( $20 \mathrm{mg} / \mathrm{kg} /$ day); TFA control, intragastric administration of TFA (13 mg/kg/day); model, intragastric administration of distilled water + rectal TNBS administration; PUFA model, intragastric administration of n-3 PUFA $(20 \mathrm{mg} / \mathrm{kg} / \mathrm{day})+$ rectal TNBS administration; and TFA model, intragastric administration of TFA $(13 \mathrm{mg} / \mathrm{kg} / \mathrm{day})+$ rectal TNBS administration. CD rat models were induced by rectal administration of TNBS (Sigma-Aldrich; Merck KGaA, Darmstadt, Germany) in ethanol $(100 \mathrm{mg} / \mathrm{kg}$ TNBS $+50 \%$ ethanol; $0.25 \mathrm{ml}$ ) four times, with a 10 day interval between each TNBS treatment (days 0, 10, 20 and 30) (21). Rats in the control, PUFA and TFA control groups were given rectal administration of $0.9 \% \mathrm{NaCl}$ solution instead of TNBS. TFA (13 mg/kg/day; Medicience Ltd., Yangzhou, China) and n-3 PUFA (20 mg $/ \mathrm{kg} /$ day; Medicience Ltd.) were administered intragastrically every day from day 0 to day 60 . We calculated the most suitable dose for rats according to the following formula: Dose for rats $=(\mathrm{X} \mathrm{mg} / \mathrm{kg} \times 70 \mathrm{~kg} \times 0.018) / 0.2 \mathrm{~kg}=6$. $3 \mathrm{X} \mathrm{mg} / \mathrm{kg}$. X denotes the effective dose for humans, $70 \mathrm{~kg}$ is the standard weight for humans, 0.018 is the ratio of the equivalent dose between humans and rats based on body surface area and $0.2 \mathrm{~kg}$ is the standard weight of a rat (22).

Necropsy. At the end of the experiment (day 60), rats were anesthetized and blood samples ( $2 \mathrm{ml}$ from each rat) were collected into tubes by cardiac puncture. Colon tissue specimens were subjected to macroscopic assessment prior to being cut and fixed in 10\% formaldehyde saline solution at room temperature for $24 \mathrm{~h}$ before histological analysis. Serum was collected following blood centrifugation at $550 \mathrm{x}$ g for $10 \mathrm{~min}$ at $4^{\circ} \mathrm{C}$. Tissue and serum samples were snap frozen in liquid nitrogen and stored at $-80^{\circ} \mathrm{C}$ until further analysis.

Blood fat and inflammatory marker detection. Blood samples were collected in tubes at day 60 by cardiac puncture. Serum content of total cholesterol (TC), triglycerides (TGs), erythrocyte sedimentation rate (ESR) and high-sensitivity C-reactive protein (hs-CRP) was determined using the Olympus AU400 Clinical Chemistry analyzer (Olympus Corporation, Tokyo, Japan).

Disease activity index (DAI) of rats. Rats were examined daily by a blinded investigator to determine the DAI, which was achieved by scoring body weight loss, stool consistency and bleeding, as described previously $(23,24)$, and scoring is described in Table I.

Colon macroscopic damage index (CMDI) of rats. The CMDI was the criteria for assessing macroscopic damage. The following numerical rating scores were employed: 0 , no ulcer 
Table I. Criteria for scoring disease activity index.

\begin{tabular}{lcll}
\hline Score & $\begin{array}{c}\text { Weight } \\
\text { loss, } \%\end{array}$ & $\begin{array}{c}\text { Stool } \\
\text { consistency }\end{array}$ & $\begin{array}{l}\text { Occult blood or } \\
\text { gross bleeding }\end{array}$ \\
\hline 0 & 0 & Normal & Negative \\
1 & $1-5$ & Loose stool & Negative \\
2 & $5-10$ & Loose stool & Hemoccult positive \\
3 & $10-15$ & Diarrhea & Hemoccult positive \\
4 & $>15$ & Diarrhea & Gross bleeding \\
\hline
\end{tabular}

Disease activity index $=$ (combined score of weight loss, stool consistency and bleeding)/3. Normal stools, well-formed pellets; loose stool, pasty stools that do not adhere to the anus; diarrhea, liquid stools that adhere to the anus.

or inflammation; 1, local hyperemia without ulcers; 2, ulceration without hyperemia; 3 , ulceration and inflammation at one site only; 4 , two or more sites of ulceration and inflammation extending $>1 \mathrm{~cm}$; and 5 , ulceration extending $>2 \mathrm{~cm}(24,25)$.

Tissue damage index (TDI) of rats. Formaldehyde-fixed colon specimens were obtained and cut into $4 \mu \mathrm{m}$ thick sections. The sections were then stained with $0.5 \%$ hematoxylin for $5 \mathrm{~min}$, followed by $0.5 \%$ eosin for $1 \mathrm{~min}$ at room temperature. Hematoxylin and eosin staining was performed via a light microscope at x100 magnification. An expert pathologist evaluated the stained samples in a blind fashion and evaluated the TDI according to previously described criteria (26), which involves scores from 0-4 (0, no signs of inflammation; 1, low level of leukocyte infiltration; 2, moderate level of leukocyte infiltration; 3 , high level of leukocyte infiltration, high vascular density and thickening of the colon wall; 4 , in addition to points mentioned for score 3 , the lesions exceed $50 \%$ of the specimens; 5 , transmural infiltration, loss of goblet cells, high vascular density and thickening of the colon wall; and 6 , in addition to points mentioned for score 5 , the lesions exceed $50 \%$ of the specimens) (24).

ELISA analysis. The serum levels of cytokines associated with local mucosal immunity, including IL-6, IL-12, tumor necrosis factor (TNF)- $\alpha$ and interferon (IFN) $-\gamma$, were measured using commercial ELISA kits (R\&D Systems, Inc., Minneapolis, MN, USA) according to the manufacturer's protocols. A standard curve was generated with each assay, with the limit of detection for IL-6, IL-12, TNF- $\alpha$ and IFN- $\gamma$ being 12.0, 5.5, 20.0 and $15.4 \mathrm{pg} / \mathrm{ml}$, respectively. Each sample was performed in triplicate.

Reverse transcription-quantitative polymerase chain reaction (RT-qPCR) analysis. All the rats in each group were sampled for RT-qPCR analysis. Total RNA was extracted from colon tissue using TRIzol (Invitrogen, Thermo Fisher Scientific, Inc., Waltham, MA, USA), according to manufacturer protocol. The extracted RNA was diluted to a concentration of $1 \mu \mathrm{g} / \mu \mathrm{l}$, and aliquots were stored at $-80^{\circ} \mathrm{C}$. RT-qPCR was performed in triplicate for each specimen using SYBR-Green PCR Master mix (Applied Biosystems; Thermo Fisher Scientific, Inc.). Total
RNA (500 ng) was used for cDNA synthesis and $1 \mu \mathrm{l}$ each reverse transcription product was added to a $9 \mu 1$ MasterMix reaction containing buffer, SYBR hydrolysis probes, Hot Start Taq polymerase and dNTPs. The reaction consisted of $0.2 \mu \mathrm{l}$ $25 \mathrm{mM}$ dNTPs, $0.5 \mu \mathrm{l} 25 \mu \mathrm{M}$ corresponding primers and $9.3 \mu \mathrm{l}$ $\mathrm{ddH}_{2} \mathrm{O}$ for PCR amplification. qPCR cycling conditions were as follows: $10 \mathrm{~min}$ pre-denaturation at $95^{\circ} \mathrm{C}$ followed by 35 or 38 cycles of $10 \mathrm{sec}$ denaturation at $95^{\circ} \mathrm{C}$ and $60 \mathrm{sec}$ annealing at $52^{\circ} \mathrm{C}$. Sequences of the primers used and each number of cycles are listed in Table II. Each experiment was performed in triplicate. The relative levels of the target mRNAs were normalized to the corresponding levels of GAPDH mRNA in the same cDNA sample using a standard curve method recommended in the LightCycler Software version 3.5 (Roche Molecular Diagnostics, Pleasanton, CA, USA).

Statistical analysis. Data are presented as the mean \pm standard deviation. Homoscedasticity tests and normal distribution were performed, and data were subsequently analyzed by one-way analysis of variance followed by the Bonferroni multiple comparisons test. $\mathrm{P}<0.05$ was considered to indicate a statistically significant difference. All statistical analyses were performed using SPSS version 13.0 (SPSS, Inc., Chicago, IL, USA).

\section{Results}

Serum fat and inflammatory indices. The results in Table III demonstrated that TC in the TFA model group was significantly higher compared with other groups $(\mathrm{P}<0.05)$, which indicates that a TFA-enriched diet may disturb fat metabolism. However, no differences were observed in the TG content between all groups. Inflammatory indices, including ESR and hs-CRP, were significantly increased in all three model groups compared with the control groups, but the n-3 PUFA model group exhibited significantly reduced levels compared with the model and TFA model groups $(\mathrm{P}<0.05$; Table III).

DAI scores of rats. DAI scores in the model, PUFA model and TFA model groups were significantly higher compared with those in control, PUFA control and TFA control groups $(\mathrm{P}<0.001$ vs. all control groups; Fig. 1). No differences were observed in the DAI scores among the three control groups, which indicate that diet intervention did not have effects in healthy rats (Fig. 1). However, a significant decrease in DAI scores was observed in the PUFA model group ( $\mathrm{P}<0.001$ vs. model group) and an increase in the TFA model group $(\mathrm{P}<0.01$ vs. model group; Fig. 1).

CMDI and TDI. CMDI and TDI indices in the model group were significantly higher compared with the three control groups $(\mathrm{P}<0.001)$. A high intake of $\mathrm{n}-3$ PUFA significantly lowered both scores, exerting a protective effect on rats with $\mathrm{CD}(\mathrm{P}<0.01$ for $\mathrm{CMDI}$ and $\mathrm{P}<0.001$ for TDI). A TFA-enriched diet significantly increased TDI scores $(\mathrm{P}<0.001)$ and $\mathrm{CMDI}$ scores were increased (without statistical significance; $\mathrm{P}>0.05$ ) compared with the model group (Fig. 2).

Pathological changes in rat colon tissue. Colon tissue in TNBS-induced CD model rats was characterized by 
Table II. Primers and product size for each target gene.

\begin{tabular}{|c|c|c|c|c|c|}
\hline \multirow[b]{2}{*}{ Gene } & \multicolumn{2}{|c|}{ Primer sequence } & \multirow{2}{*}{$\begin{array}{l}\text { Length, } \\
\text { bp }\end{array}$} & \multirow{2}{*}{$\begin{array}{l}\text { Number of } \\
\text { cycles }\end{array}$} & \multirow{2}{*}{$\begin{array}{c}\text { Annealing } \\
\text { temperature, }{ }^{\circ} \mathrm{C}\end{array}$} \\
\hline & Forward & Reverse & & & \\
\hline PPAR- $\gamma$ & 5'-ATTACGATAGCCGTTCC-3' & 5'-TAATGCTATCGGCAATT-3' & 190 & 35 & 52 \\
\hline NFAT & 5'-GTACCGTACATGCGTTCA-3' & 5'-CATGGCATGTACGCAAGT-3' & 201 & 35 & 52 \\
\hline IL-2 & 5'-CGTATCATGCACTGCATA-3' & 5'-GCATAGTACGTGACGTAT-3' & 186 & 38 & 52 \\
\hline IL-4 & 5'-ATCCGATAACGTACCGTAC-3' & 5'-TAGGCTATTGCATGGCATG-3' & 173 & 35 & 52 \\
\hline GAPDH & 5'-GAATCTGGTGGCTGTGGA-3' & 5'-ССCTGAAAGGCTTGGTCT-3' & 202 & 35 & 52 \\
\hline
\end{tabular}

PPAR, peroxisome proliferator-activated receptor- $\gamma$; NFAT, nuclear factor of activated T-cells; IL, interleukin.

Table III. Serum fat and inflammatory index in rats in each group.

\begin{tabular}{lcccc}
\hline Group & $\begin{array}{c}\text { Triglyceride, } \\
\mathrm{mmol} / \mathrm{l}\end{array}$ & $\begin{array}{c}\text { Total cholesterol, } \\
\mathrm{mmol} / \mathrm{l}\end{array}$ & $\begin{array}{c}\text { Erythrocyte sedimentation } \\
\text { rate }, \mathrm{mm} / \mathrm{h}\end{array}$ & $\begin{array}{c}\text { High-sensitivity C-reactive } \\
\text { protein, } \mathrm{mg} / \mathrm{l}\end{array}$ \\
\hline Control & $1.21 \pm 0.22$ & $1.72 \pm 0.42^{\mathrm{a}}$ & $12.00 \pm 4.32^{\mathrm{a}-\mathrm{c}}$ & $2.11 \pm 0.28^{\mathrm{a}-\mathrm{c}}$ \\
PUFA control & $1.32 \pm 0.35$ & $1.69 \pm 0.61^{\mathrm{a}}$ & $13.41 \pm 4.36^{\mathrm{a}-\mathrm{c}}$ & $2.78 \pm 0.34^{\mathrm{a}-\mathrm{c}}$ \\
TFA control & $1.37 \pm 0.28$ & $2.14 \pm 0.42^{\mathrm{a}}$ & $15.67 \pm 4.84^{\mathrm{a}-\mathrm{c}}$ & $2.65 \pm 0.27^{\mathrm{a}-\mathrm{c}}$ \\
Model & $1.17 \pm 0.26$ & $2.01 \pm 0.53^{\mathrm{a}}$ & $23.07 \pm 4.90^{\mathrm{b}}$ & $9.05 \pm 2.50^{\mathrm{b}}$ \\
PUFA model & $1.39 \pm 0.33$ & $1.97 \pm 0.45^{\mathrm{a}}$ & $19.34 \pm 5.07^{\mathrm{a}, \mathrm{c}}$ & $6.15 \pm 1.75^{\mathrm{a}, \mathrm{c}}$ \\
TFA model & $1.37 \pm 0.30$ & $3.01 \pm 0.55$ & $24.05 \pm 4.82^{\mathrm{b}}$ & $8.98 \pm 2.63^{\mathrm{b}}$ \\
\hline
\end{tabular}

Data are presented as the mean \pm standard deviation, $\mathrm{n}=15$ per group. ${ }^{\mathrm{a}} \mathrm{P}<0.05$ vs. TFA model group; ${ }^{\mathrm{b}} \mathrm{P}<0.05$ vs. PUFA model group; ${ }^{\mathrm{c}} \mathrm{P}<0.05$ vs. model group. PUFA, polyunsaturated fatty acid; TFA, trans-fatty acid.

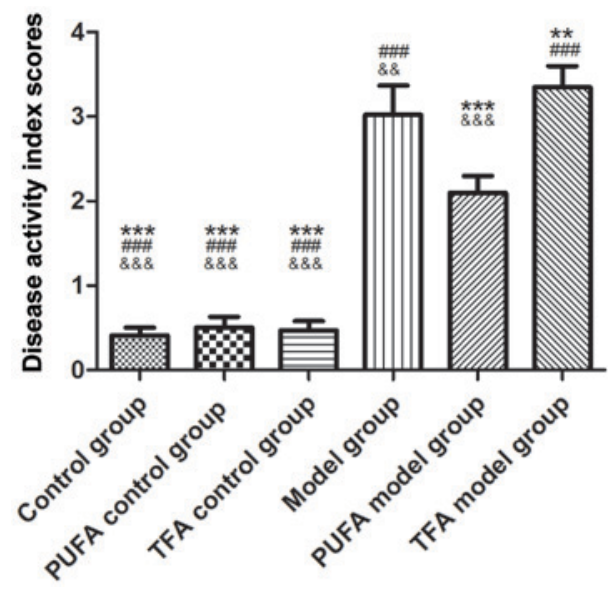

Figure 1. Disease activity index scores of rats in each group. Data in this figure represent results at day 60 only and are presented as the mean \pm standard deviation. PUFA, polyunsaturated fatty acid; TFA, trans fatty acid. ${ }^{* *} \mathrm{P}<0.01,{ }^{* * *} \mathrm{P}<0.001$ vs. model group; ${ }^{\# \# \#} \mathrm{P}<0.001$ vs. PUFA model group; ${ }^{\& \&} \mathrm{P}<0.01,{ }^{\& \& \&} \mathrm{P}<0.001$ vs. TFA model group.

infiltration of the lamina propria with inflammatory cells and crypt abscesses (Fig. 3). Following intervention with n-3 PUFA treatment, a marked improvement in the level inflammation was observed (Fig. 3). However, TFA intervention appeared to aggravate inflammation with epithelioid granulomas, which are typical pathological changes of $\mathrm{CD}$ (Fig. 3).

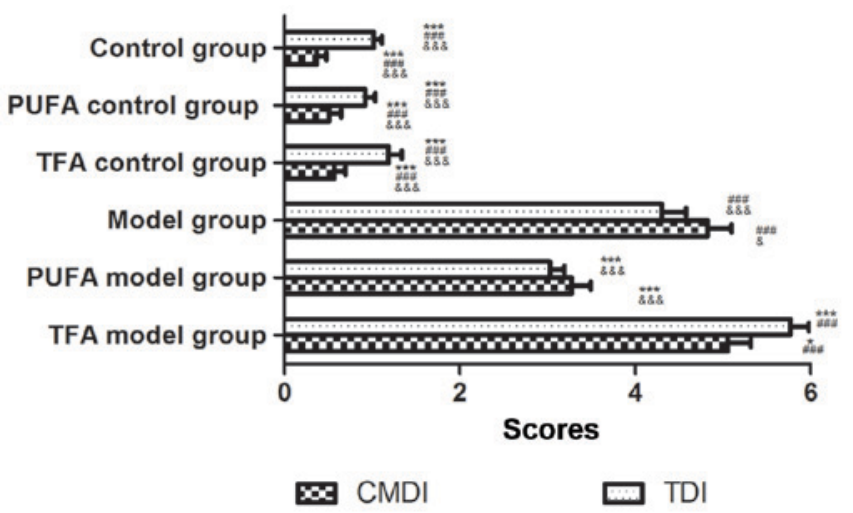

Figure 2. Evaluation of CMDI and TDI scores in each group. Data are presented as the mean \pm standard deviation. CMDI, colon macroscopic damage index; TDI, tissue damage index; PUFA, polyunsaturated fatty acid; TFA, trans fatty acid. ${ }^{*} \mathrm{P}<0.05,{ }^{* * * *} \mathrm{P}<0.001$ vs. model group; ${ }^{\# \# \#} \mathrm{P}<0.001$ vs. PUFA model group; ${ }^{\&} \mathrm{P}<0.05,{ }^{\& \& \&} \mathrm{P}<0.001$ vs. TFA model group.

Serum levels of cytokines in each group detected by ELISA. Marked increases in IL-6, IL-12, TNF- $\alpha$ and IFN- $\gamma$ serum levels were observed in the three model groups compared with the three control groups (Fig. 4), indicating that TNBS intervention successfully altered local mucosal immunity. IL-6, IL-12 and TNF- $\alpha$ concentrations were significantly decreased in the PUFA model group compared with the model group $(\mathrm{P}<0.05$; Fig. 4). However, a TFA-enriched diet appeared to 
A
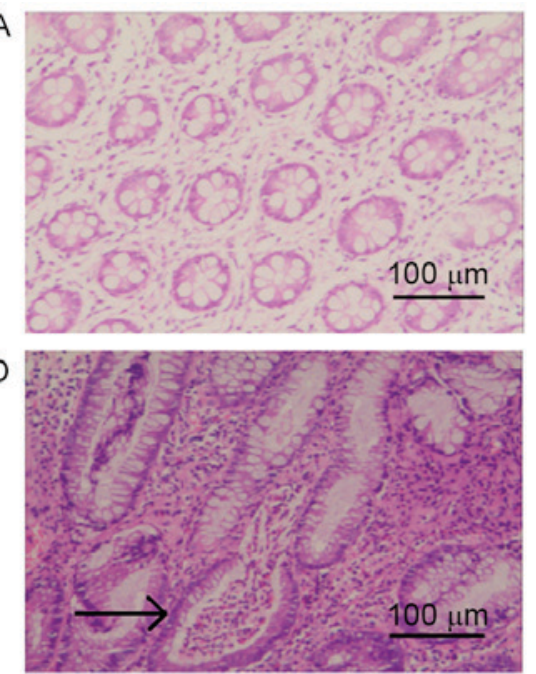

B

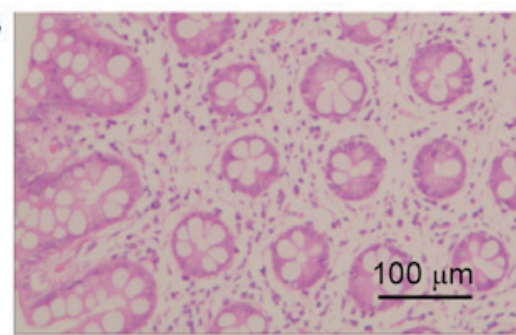

E

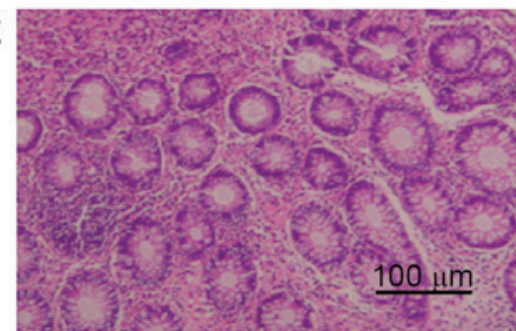

C

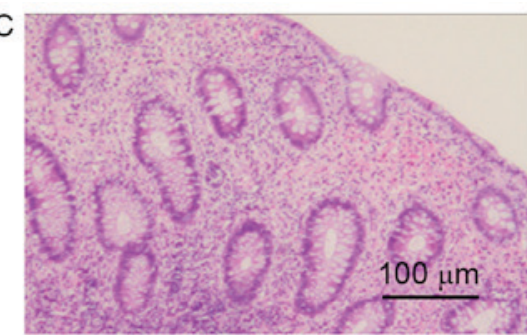

F

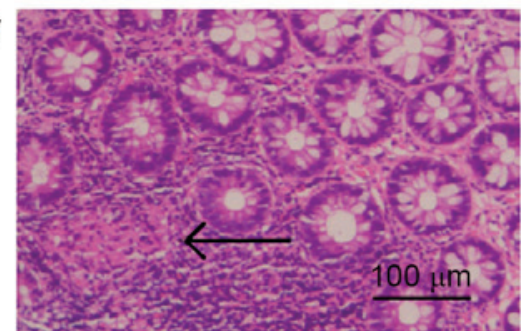

Figure 3. Pathological changes in the rat colon stained with hematoxylin and eosin in each group. (A) Colonic tissues in the control group with integrated architecture exhibiting no inflammation. Colonic tissues in the (B) n-3 PUFA control group and (C) TFA control group exhibiting mild or no inflammation. (D) Colonic tissues in 2,4,6-trinitrobenzene sulfonic acid-induced model group exhibiting increased inflammatory cell infiltration and typical crypt abscesses (arrow). (E) Colonic tissues in the n-3 PUFA model group exhibiting uneven distribution of inflammation. (F) Colonic tissues in the TFA model group exhibiting epithelioid granulomas in addition to inflammatory cell infiltration (arrow). Magnification, x100. PUFA, polyunsaturated fatty acid; TFA, trans fatty acid.

A

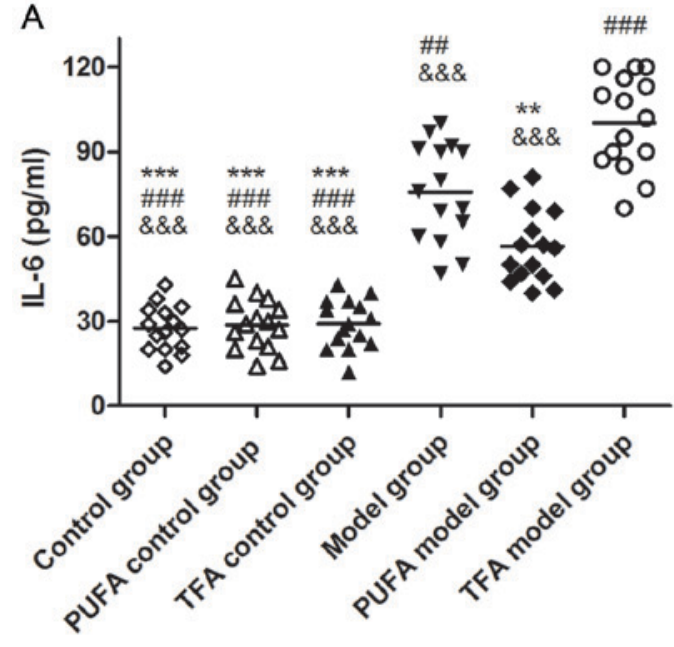

C

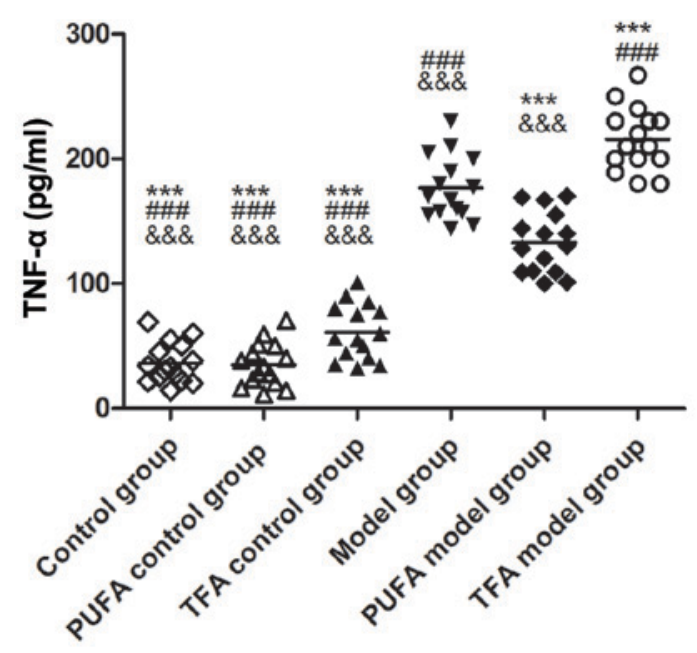

B

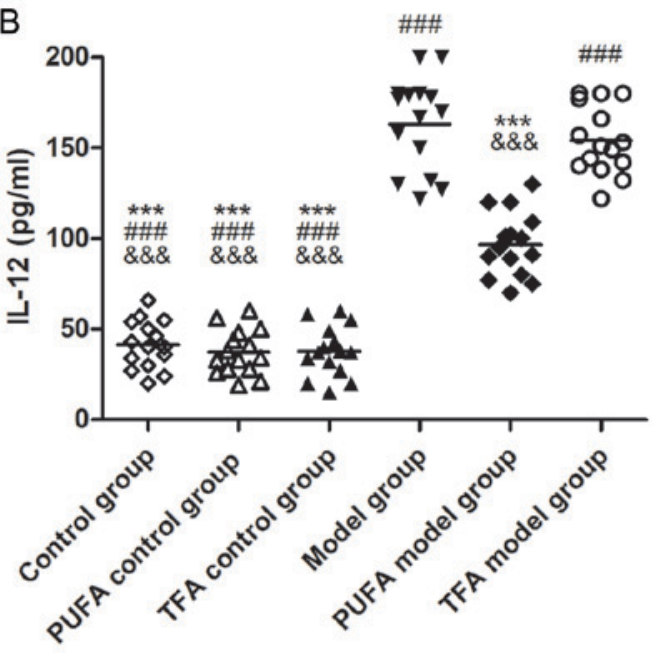

D

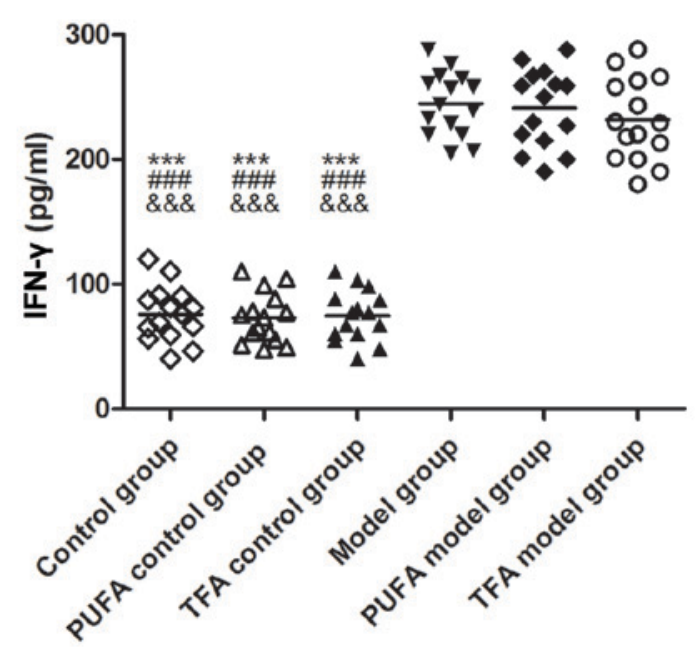

Figure 4. Concentration of cytokines in the serum detected by ELISA in each group. ELISA was performed to determine the levels of (A) IL-6, (B) IL-12, (C) TNF- $\alpha$ and (D) IFN- $\gamma$ in the serum of rats in each treatment group. Data points indicate the individual values of cytokines in single biopsies and horizontal bars represent the median value. IL, interleukin; TNF, tumor necrosis factor; IFN, interferon; PUFA, polyunsaturated fatty acid; TFA, trans fatty acid. ** P $<0.01$, ${ }^{* * * *} \mathrm{P}<0.001$ vs. model group; ${ }^{\# \#} \mathrm{P}<0.01,{ }^{\# \# \#} \mathrm{P}<0.001$ vs. PUFA model group; ${ }^{\& \& \&} \mathrm{P}<0.001$ vs. TFA model group. 


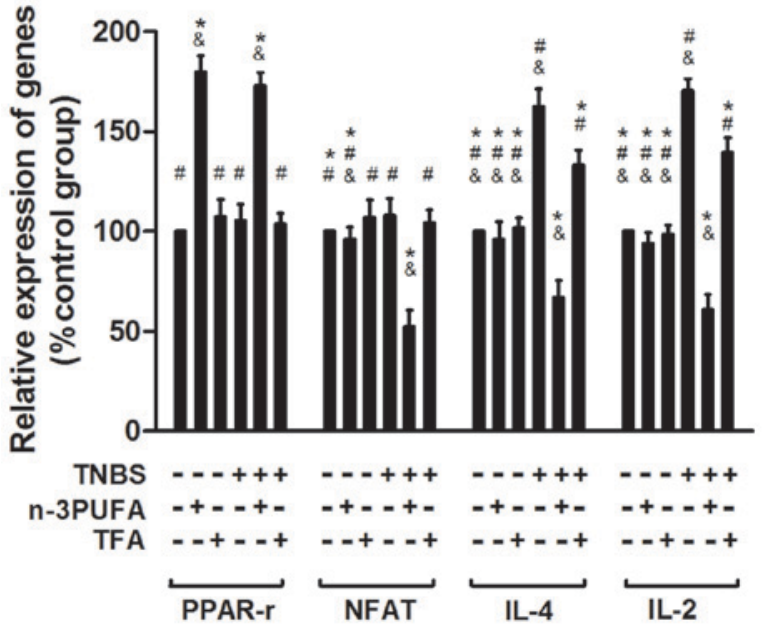

Figure 5. Relative mRNA expression of genes associated with the PPAR- $\gamma /$ NFAT pathway in each group. The relative mRNA expression of PPAR- $\gamma$, NFAT, IL-4 and IL-2 was analyzed in colon samples taken from rats in each treatment group by reverse transcription-quantitative polymerase chain reaction, and expression was presented normalized to the control group. PPAR, peroxisome proliferator-activated receptor; NFAT, nuclear factor of activated T-cells; IL, interleukin; TNBS, 2,4,6-trinitrobenzene sulfonic acid; PUFA, polyunsaturated fatty acid; TFA, trans fatty acid. ${ }^{*} \mathrm{P}<0.05$ vs. mode group, ${ }^{\#} \mathrm{P}<0.05$ vs. PUFA model group and ${ }^{\circledR} \mathrm{P}<0.05$ vs. TFA model group.

worsen local mucosal immunity as levels of serum IL-6 and TNF- $\alpha$ were significantly increased in the TFA model group compared with the model group $(\mathrm{P}<0.05$; Fig. 4).

Expression of PPAR- $\gamma / N F A T$-associated genes detected by $R T-q P C R$. The mRNA expression of genes associated with the PPAR- $\gamma /$ NFAT pathway, including PPAR- $\gamma$, NFAT, IL-2 and IL-4, was detected by RT-qPCR. A significant increase in the expression of the proinflammatory cytokines IL-2 and IL-4 was observed in the model and TFA model groups $(\mathrm{P}<0.05$; Fig. 5) compared with the control group. However, IL-2 and IL-4 expression was reduced in the n-3PUFA model group, indicating a potential anti-inflammatory effect of n-3 PUFA diet intervention (Fig. 5). Furthermore, the expression of PPAR- $\gamma$ was enhanced in the n-3 PUFA intervention group compared with model and TFA model groups (Fig. 5), which indicates that PPAR- $\gamma$ may be activated by an $n-3$ PUFA-enriched diet. In addition, the expression of NFAT was reduced in the n-3 PUFA model group compared with model and TFA model groups (Fig. 5), indicating that n-3 PUFA may inhibit NFAT, potentially via the activation of PPAR- $\gamma$ in TNBS-induced CD rats.

\section{Discussion}

At present, no curative treatment is available for CD. Traditional treatments, including aminosalicylates, corticosteroids, immunomodulating drugs and biological agents, are associated with limitations due to adverse side effects (27-29). Therefore, the identification of alternative therapeutic strategies that are effective with reduced side effects is necessary. Previous studies have demonstrated the association between dietary fat and IBD. Borniquel et al (30) reported that dietary conjugated linoleic acid ameliorated colonic inflammation induced by dextran sulfate sodium in mice. In addition, another study demonstrated the efficacy of short chain fatty acids in accelerating clinical disease in an IL-10 ${ }^{-/}$mouse model (31).

Dietary n-3 PUFA is present in fish oil. It was reported to ameliorate intestinal inflammation in a colitis rat model. However, the underlying mechanisms were not determined (32). Based on this, the present study aimed to determine whether a similar protective effect of dietary n-3 PUFA may be observed in CD. Thus, TNBS-induced CD rat models were established, which were characterized as IL-12 driven and resembled the alterations observed in patients with CD (33). An n-3 PUFA diet was employed as an intervention strategy. The present study successfully established CD rat models with pathological changes such as massive transmural infiltration of inflammatory cells, typical epithelioid granulomas and crypt abscess formation. The results demonstrated that dietary supplementation with n-3 PUFA ameliorated the symptoms of experimental CD rats, with lower DAI, CDI and CMDI scores and milder changes demonstrated by pathological observation. In addition, the results indicated that the protective effects of n-3 PUFA may involve activation of the PPAR- $\gamma /$ NFAT pathway, which ultimately led to improvements in mucosal inflammation and amelioration of tissue damage. This study, to the best of our knowledge, was the first to report the protective effect of dietary n-3 PUFA on CD rats and to identify potential underlying mechanisms.

The role of PPAR- $\gamma$ in the etiology and treatment of colitis is a subject of great interest. Thiazolidinediones, PPAR- $\gamma$ ligands, have been previously reported to decrease the severity of UC in rats (34). Furthermore, PPAR- $\gamma^{+/-}$heterozygous mice exhibited increased susceptibility to experimental-induced colitis, which further indicated a role for PPAR- $\gamma$ in the maintenance of gut homeostasis $(35,36)$. Despite these observations, the role of PPAR- $\gamma$ in experimental CD rats and its association with dietary fatty acid intervention has not been previously reported. It is established that n-3 PUFAs and their metabolites are endogenous PPAR- $\gamma$ ligands (37). The results of the current study revealed that $n-3$ PUFA intake activated PPAR- $\gamma$ expression in healthy rats and TNBS-induced CD rats. Therefore, the protective effects of n-3 PUFA may be attributed to the activation and increased expression of PPAR- $\gamma$, which was consistent with a previous study (30). PPAR- $\gamma$ usually exists as a heterodimer with retinoid $\mathrm{X}$ receptor, and has been reported to be associated with PPAR response elements in the regulation of NFAT, a transcription factor that binds to the IL-2 and IL-4 promoters and is necessary for gene transcription $(18,38)$. The present study demonstrated that an n-3 PUFA-enriched diet inhibited the expression of NFAT in CD rats. In addition, the gene expression of the proinflammatory cytokines IL-2 and IL-4 was reduced, which may contribute to ameliorated mucosal localized inflammation in n-3 PUFA intervention CD rats. However, no difference in NFAT expression was observed between healthy rats with or without n-3 PUFA, which indicates that factors other than n-3 PUFA and PPAR- $\gamma$ may be involved in the modulation of NFAT expression, and further investigation is required.

TFAs are steric isomers of cis unsaturated fatty acids with distinct differences in biological effects. TFAs are primarily present in dairy products and meats, and are generated during the manufacturing process. Western-style diets usually contain high levels of TFAs (39). Recently, a number of reports have 
demonstrated that TFA intake is a risk factor for diabetes mellitus, coronary heart disease and hyperlipemia $(40,41)$. The present study demonstrated that TFA intake enhanced the risk of hypertriglyceridemia in CD rats, which was consistent with the results of a previous study (42). However, no differences in blood fat levels were observed in healthy rats despite the different diets, which indicated an association between intestinal inflammation and susceptibility to blood lipid disorders. Furthermore, the results of the current study revealed that a TFA-enriched diet enhanced the serum levels of IL-6 and TNF- $\alpha$, exacerbated mucosal localized inflammation determined by pathological observation and increased the gene expression of IL-2 and IL-4. However, TFA exhibited no effect on the gene expression of PPAR- $\gamma$ and NFAT, indicating that TFA may worsen inflammatory in CD rats via pathways other than PPAR- $\gamma /$ NFAT.

In conclusion, the present study demonstrated a potent anti-inflammatory effect of dietary n-3 PUFA in experimental $\mathrm{CD}$ rats, and the protective effect of this fatty acid may involve the activation of PPAR- $\gamma$ and inhibition of NFAT. Therefore, an n-3 PUFA-enriched diet, with few adverse side effects and established mechanisms, may be a novel therapeutic approach for patients with CD. However, further investigation is required. An improved mechanistic understanding in combination with more comprehensive data from well-designed clinical studies will provide the basis for accelerating the development of nutrition-based therapies against CD.

\section{Acknowledgements}

The present study was supported by grants from the National Natural Science Foundation of China (grant no. 81370498) and the Natural Science Foundation of Guangdong Province (grant no. 2011B031800097). The funders had no role in the study design, data collection and analysis, decision to publish or preparation of the manuscript. The authors thank Professor Yongfei $\mathrm{Wu}$ from the Department of Neurology, Northwestern University Feinberg School of Medicine (Chicago, IL, USA) for his assistance in improving the language.

\section{References}

1. Abraham $\mathrm{C}$ and Cho JH: Inflammatory bowel disease. $\mathrm{N}$ Engl J Med 361: 2066-2078, 2009

2. Khor B, Gardet A and Xavier RJ: Genetics and pathogenesis of inflammatory bowel disease. Nature 474: 307-317, 2011.

3. Asakura H, Suzuki K, Kitahora T and Morizane T: Is there a link between food and intestinal microbes and the occurrence of Crohn's disease and ulcerative colitis? J Gastroenterol Hepatol 23 . 1794-1801, 2008.

4. Thia KT, Loftus EV Jr, Sandborn WJ and Yang SK: An update on the epidemiology of inflammatory bowel disease in Asia. Am J Gastroenterol 103: 3167-3182, 2008.

5. Nakanishi S, Nagano C, Miyahara M and Sawano F: Sex differences in the association between the eicosapentaenoic acid/arachidonic acid ratio and the visceral fat area among patients with type 2 diabetes. Intern Med 55: 1269-1274, 2016.

6. Borgeraas H,Hertel JK, Seifert R, Berge RK, Bohov P, Ueland PM, Nygård $\mathrm{O}$ and Hjelmesæth J: Serum trans fatty acids, asymmetric dimethylarginine and risk of acute myocardial infarction and mortality in patients with suspected coronary heart disease: A prospective cohort study. Lipids Health Dis 15: 38, 2016.

7. Ananthakrishnan AN, Khalili H, Konijeti GG, Higuchi LM, de Silva P, Fuchs CS, Willett WC, Richter JM and Chan AT: Long-term intake of dietary fat and risk of ulcerative colitis and Crohn's disease. Gut 63: 776-784, 2014.
8. Marion-Letellier R, Savoye G, Beck PL, Panaccione R and Ghosh S: Polyunsaturated fatty acids in inflammatory bowel diseases: A reappraisal of effects and therapeutic approaches. Inflamm Bowel Dis 19: 650-661, 2013.

9. Yang Y, Lu N, Chen D, Meng L, Zheng Y and Hui R: Effects of n-3 PUFA supplementation on plasma soluble adhesion molecules: A meta-analysis of randomized controlled trials. Am J Clin Nutr 95: 972-980, 2012.

10. Calder PC: Mechanisms of action of (n-3) fatty acids. J Nutr 142 (Suppl): 592S-599S, 2012.

11. Adachi M, Kurotani R, Morimura K, Shah Y, Sanford M, Madison BB, Gumucio DL, Marin HE, Peters JM, Young HA and Gonzalez FJ: Peroxisome proliferator activated receptor gamma in colonic epithelial cells protects against experimental inflammatory bowel disease. Gut 55: 1104-1113, 2006.

12. Su CG, Wen X, Bailey ST, Jiang W, Rangwala SM, Keilbaugh SA, Flanigan A, Murthy S, Lazar MA and Wu GD: A novel therapy for colitis utilizing PPAR-gamma ligands to inhibit the epithelial inflammatory response. J Clin Invest 104: 383-389, 1999.

13. Bassaganya-Riera J, Viladomiu M, Pedragosa M, De Simone C and Hontecillas R: Immunoregulatory mechanisms underlying prevention of colitis-associated colorectal cancer by probiotic bacteria. PLoS One 7: e34676, 2012.

14. Zeng C, Xiao JH, Chang MJ and Wang JL: Beneficial effects of THSG on acetic acid-induced experimental colitis: Involvement of upregulation of PPAR- $\gamma$ and inhibition of the Nf-Kb inflammatory pathway. Molecules 16: 8552-8568, 2011.

15. Hontecillas R, Horne WT, Climent M, Guri AJ, Evans C, Zhang Y, Sobral BW and Bassaganya-Riera J: Immunoregulatory mechanisms of macrophage PPAR- $\gamma$ in mice with experimental inflammatory bowel disease. Mucosal Immunol 4: 304-313, 2011.

16. Nakajima A, Wada K, Miki H, Kubota N, Nakajima N, Terauchi Y, Ohnishi S, Saubermann LJ, Kadowaki T, Blumberg RS, et al: Endogenous PPAR gamma mediates anti-inflammatory activity in murine ischemia-reperfusion injury. Gastroenterology 120: 460-469, 2001

17. Raman P, Kaplan BL, Thompson JT, Vanden Heuvel JP and Kaminski NE: 15-Deoxy-delta12,14-prostaglandin J2-glycerol ester, a putative metabolite of 2-arachidonyl glycerol, activates peroxisome proliferator activated receptor gamma. Mol Pharmacol 80: 201-209, 2011

18. Chung SW, Kang BY and Kim TS: Inhibition of interleukin-4 production in $\mathrm{CD} 4^{+} \mathrm{T}$ cells by peroxisome proliferator-activated receptor-gamma (PPAR-gamma) ligands: Involvement of physical association between PPAR-gamma and the nuclear factor of activated T cells transcription factor. Mol Pharmacol 64: 1169-1179, 2003.

19. National Research Council: Guide For The Care And Use Of Laboratory Animals. No. 85-23. National Academies Press, Washington, DC, 1996.

20. Kilkenny C, Browne WJ, Cuthill IC, Emerson M and Altman DG: Improving bioscience research reporting: The ARRIVE guidelines for reporting animal research. PLoS Biol 8: e1000412, 2010.

21. Mizoguchi A: Animal models of inflammatory bowel disease. Prog Mol Biol Transl Sci 105: 263-320, 2012.

22. Wei W: Pharmacokinetics and bioavailability of drug metabolism. In: Experimental Methodology of Pharmacology. 6th edition. People's Medical Publishing Company, Guangzhou, 2010.

23. Ito R, Shin-Ya M, Kishida T, Urano A, Takada R, Sakagami J, Imanishi J, Kita M, Ueda Y, Iwakura Y, et al: Interferon-gamma is causatively involved in experimental inflammatory bowel disease in mice. Clin Exp Immunol 146: 330-338, 2006.

24. Yao JY, Lu Y, Zhi M, Li CJ, Hu PJ and Gao X: Inhibition of the interleukin-23/interleukin-17 pathway by anti-interleukin-23p19 monoclonal antibody attenuates 2,4,6-trinitrobenzene sulfonic acid-induced Crohn's disease in rats. Mol Med Rep 10: 2105-2110, 2014.

25. Ding H, Gan HZ, Fan WJ, Cao LY, Xu JM and Mei Q: Homocysteine promotes intestinal fibrosis in rats with trinitrobenzene sulfonic acid-induced colitis. Dig Dis Sci 60: 375-381, 2015.

26. Zingarelli B, Hake PW, Burroughs TJ, Piraino G, O'Connor M and Denenberg A: Activator protein-1 signalling pathway and apoptosis are modulated by poly(ADP-ribose) polymerase-1 in experimental colitis. Immunology 113: 509-517, 2004.

27. Deepak P and Loftus EV Jr: Ustekinumab in treatment of Crohn's disease: Design, development, and potential place in therapy. Drug Des Devel Ther 10: 3685-3698, 2016. 
28. Bassaganya-Riera J, Reynolds K, Martino-Catt S, Cui Y, Hennighausen L, Gonzalez F, Rohrer J, Benninghoff AU and Hontecillas R: Activation of PPAR gamma and delta by conjugated linoleic acid mediates protection from experimental inflammatory bowel disease. Gastroenterology 127: 777-791, 2004.

29. Viladomiu M,Hontecillas R, YuanL,Lu Pand Bassaganya-Riera J: Nutritional protective mechanisms against gut inflammation. J Nutr Biochem 24: 929-939, 2013.

30. Borniquel S, Jädert C and Lundberg JO: Dietary conjugated linoleic acid activates PPAR $\gamma$ and the intestinal trefoil factor in SW480 cells and mice with dextran sulfate sodium-induced colitis. J Nutr 142: 2135-2140, 2012.

31. Bassaganya-Riera J, DiGuardo M, Viladomiu M, de Horna A, Sanchez S, Einerhand AW, Sanders L and Hontecillas R: Soluble fibers and resistant starch ameliorate disease activity in interleukin-10-deficient mice with inflammatory bowel disease. J Nutr 141: 1318-1325, 2011.

32. Lian M, Luo W, Sui Y, Li Z and Hua J: Dietary n-3 PUFA protects mice from con A induced liver injury by modulating regulatory T cells and PPAR- $\gamma$ expression. PLoS One 10: e0132741, 2015.

33. Liu J, Zhou F, Chen Q, Kang A, Lu M, Liu W, Zang X, Wang G and Zhang J: Chronic inflammation up-regulates P-gp in peripheral mononuclear blood cells via the STAT3/Nf-kb pathway in 2,4,6-trinitrobenzene sulfonic acid-induced colitis mice. Sci Rep 5: 13558, 2015.

34. Lytle C, Tod TJ, Vo KT, Lee JW, Atkinson RD and Straus DS: The peroxisome proliferator-activated receptor gamma ligand rosiglitazone delays the onset of inflammatory bowel disease in mice with interleukin 10 deficiency. Inflamm Bowel Dis 11: 231-243, 2005.
35. Speca S, Rousseaux C, Dubuquoy C, Rieder F, Vetuschi A Sferra R, Giusti I, Bertin B, Dubuquoy L, Gaudio E, et al: Novel PPAR $\gamma$ modulator GED-0507-34 levo ameliorates inflammation-driven intestinal fibrosis. Inflamm Bowel Dis 22: 279-292, 2016.

36. Kundu P, Ling TW, Korecka A, Li Y, D'Arienzo R, Bunte RM, Berger T, Arulampalam V, Chambon P, Mak TW, et al: Absence of intestinal PPAR $\gamma$ aggravates acute infectious colitis in mice through a lipocalin-2-dependent pathway. PLoS Pathog 10: e1003887, 2014.

37. Hwang D: Fatty acids and immune responses-a new perspective in searching for clues to mechanism. Annu Rev Nutr 20: 431-456, 2000.

38. Kim HB, Kumar A, Wang L, Liu GH, Keller SR, Lawrence JC Jr, Finck BN and Harris TE: Lipin 1 represses NFATc4 transcriptional activity in adipocytes to inhibit secretion of inflammatory factors. Mol Cell Biol 30: 3126-3139, 2010

39. Mozaffarian D, Katan MB, Ascherio A, Stampfer MJ and Willett WC: Trans fatty acids and cardiovascular disease. N Engl J Med 354: 1601-1613, 2006.

40. Micha R and Mozaffarian D: Trans fatty acids: Effects on cardiometabolic health and implications for policy. Prostaglandins Leukot Essent Fatty Acids 79: 147-152, 2008.

41. Ganguly R and Pierce GN: Trans fat involvement in cardiovascular disease. Mol Nutr Food Res 56: 1090-1096, 2012.

42. Okada Y, Tsuzuki Y, Ueda T, Hozumi H, Sato S, Hokari R, Kurihara C, Watanabe C, Tomita K, Komoto S, et al: Trans fatty acids in diets act as a precipitating factor for gut inflammation? J Gastroenterol Hepatol 28 (Suppl 4): S29-S32, 2013. 